\title{
Pattern of treatment of behavioural and psychological symptoms of dementia and pain: evidence on pharmacoutilization from a large real-world sample and from a centre for cognitive disturbances and dementia
}

\author{
Damiana Scuteri ${ }^{1}$ (D) $\cdot$ Marilù Vulnera $^{2} \cdot$ Brunella Piro $^{2} \cdot$ Roberto Bruno Bossio $^{3} \cdot$ Luigi Antonio Morrone $^{1}$ (D)

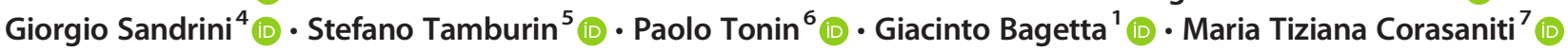

Received: 8 April 2020 / Accepted: 10 September 2020 / Published online: 15 September 2020

(C) The Author(s) 2020

\begin{abstract}
Purpose Data concerning the number of diagnoses and of the drugs prescribed to patients affected by dementia are still scarce. Here we test whether or not (1) prescription of symptomatic drugs against Alzheimer's disease (AD) may approximate the number of patients affected by dementia in Italy and (2) adherence to this treatment affects the pattern of prescription of drugs (i.e. antipsychotics and antidepressants) for behavioural and psychological symptoms of dementia (BPSD) and the previously reported limited prescription of analgesics.

Methods This retrospective observational study concerns 84,235 subjects older than 60 years and registered in the provincial prescription database of the health district of Cosenza accounting for a population of 298,000 inhabitants. The prescribing pattern of antipsychotics, antidepressants, and analgesics has been investigated in patients receiving concurrent prescriptions of acetylcholinesterase inhibitors (AChEI) and/or memantine. Data from a single centre for cognitive disturbances and dementia (CDCD) in the same health district were used to explore at which stage dementia was diagnosed. The study was approved by Calabria Region Ethical Committee no. 31/2017 and registered on October 31, 2017.

Results The data show that 859 patients are treated with AChEI and/or memantine; 420 patients (48.89\%) receive at least $80 \%$ of the recommended medications. CDCD data indicate a delay in dementia diagnosis, which often was made when the patients were moderately to severely demented (Mini Mental State Examination, MMSE $\leq 20$ ). Adherence did not influence prescription of most of the drugs explored, but use of non-steroidal anti-inflammatory drugs was higher in non-adherent patients. Antipsychotics and antidepressants are frequently used (20.61-20.71\% and 42.37-51.43\%, respectively), and this, at least in part, might stem from the observed under-treatment of chronic pain (opioids are prescribed in the $4.76 \%$ and $12.46 \%$ of adherent and non-adherent patients and gabapentin and pregabalin are used in the $4.29 \%$ and $4.07 \%$ of adherent and non-adherent patients respectively), resulting in more frequent BPSD. $16.43 \%$ of patients receive antipsychotics for longer than 6-12 weeks.

Conclusion This 2-year period study, including a wide cohort of community demented patients, shows that dementia is diagnosed late and that prevalence of BPSD prescriptions is high and not impacted by adherence to anti-dementia drugs. The rate of prescription of potentially harmful antipsychotics and antidepressants appears to be high though whether the concomitantly

Giacinto Bagetta

g.bagetta@unical.it

1 Pharmacotechnology Documentation and Transfer Unit, Section of Preclinical and Translational Pharmacology, Department of Pharmacy, Health and Nutritional Sciences, University of Calabria, Rende, Italy

2 Pharmacovigilance Territorial Service, Pharmaceutical Department, Provincial Health Authority, Cosenza, Italy

3 Center for Diagnosis and Cure of Dementia, Neurology Service of the Health District of Cosenza, Provincial Health Authority,

Cosenza, Italy

4 Department of Brain and Behavioural Sciences, IRCCS C. Mondino Foundation Neurologic Institute, University of Pavia, Pavia, Italy

5 Department of Neurosciences, Biomedicine and Movement Sciences, University of Verona, Verona, Italy

6 Regional Center for Serious Brain Injuries, S. Anna Institute, Crotone, Italy

7 Department of Health Science, University Magna Graecia, 88100 Catanzaro, Italy
\end{abstract}


observed limited prescription of analgesics might be a contributing factor needs to be further investigated. Our data support the development of strategies to improve the management of BPSD.

Keywords Alzheimer's disease $\cdot$ BPSD $\cdot$ Pain $\cdot$ Antipsychotics $\cdot$ Antidepressants $\cdot$ Analgesics

\section{Introduction}

Fifty million people suffer from dementia worldwide, and the most common form is represented by Alzheimer's disease (AD) [1]. The lack of a definite etiopathogenesis makes the discovery of disease-modifying drugs difficult (see $[2,3]$ ). Several factors contribute to delayed diagnosis of dementia $[4,5]$, and this means the two-thirds of all cases go missed in primary care $[6,7]$. Moreover, the complexity and individual variability of the clinical manifestations of dementia and the paucity of treatment options, among other factors, prompt the occurrence of appropriate symptomatic strategies [6, 8].

The large majority (97\%) of patients suffering from dementia develops neuropsychiatric symptoms [9-11], consisting in disturbances of behaviour, mood, thought, and perception (see [12]), known as behavioural and psychological symptoms of dementia (BPSD). Treatment of BPSD is a hard challenge, and it is based on the approved use of the atypical antipsychotic risperidone for no longer than 6-12 weeks (see [13]). The use of antipsychotics in demented patients is accompanied by an increased risk of mortality [14]. Quite importantly, chronic pain afflicts $72 \%$ of the oldest old (i.e. over 85 years old) patients $[15,16]$. In particular, $60-80 \%$ of demented patients living in nursing homes are estimated to suffer from pain [17]. The impaired communication skills of patients affected by severe dementia limit their self-report of pain, thus causing under-detection and under-treatment of pain, often contributing to BPSD and agitation $[18,19]$. Moreover, it is even more difficult to separate different types of pain, e.g. neuropathic vs nociceptive [17]. Accurate analgesic treatment provides reduction of agitation, and the treatment of pain can reduce the use of unnecessary neuroleptics in demented patients [19]. BPSD include depressive symptoms that can be linked to unrelieved pain. Incidentally, persistent and chronic pain per se represents risk factors for cognitive decline and dementia (see [20-22]). Previous work from our group has demonstrated accuracy of treatment of inflammatory pain, but limited access to the treatment of chronic and neuropathic pain in demented patients in Calabria in the period 2014-2016 [23, 24].

Here we report the results of a retrospective observational study (2-year period ranging from 2017 to 2018). The use of antipsychotics, antidepressants, and analgesics was investigated in patients receiving concurrent prescriptions of acetylcholinesterase inhibitors (AChEI) and/or memantine; the data were derived from a database of a provincial health district accounting for a population of 298,000 inhabitants. Under these experimental conditions, here we also report the pattern of prescription of analgesics because, despite the above described relationship between pain and BPSD, little data exist in the literature. In addition, data from a single centre for cognitive disturbances and dementia (CDCD) in the same health district were used to explore at which stage dementia was diagnosed.

\section{Materials and methods}

\section{Design of the study}

This retrospective observational study has been carried out in collaboration with the Calabrian pharmacovigilance territorial service and the CDCD of the provincial health district of Cosenza (Calabria, Italy). Anonymized data have been extracted from the regional drug reimbursement and prescription database including all the prescriptions of drugs reimbursed by the National Health System (NHS). Collected data are a comprehensive reflection of dementia patients on the basis of anti-dementia symptomatic treatment. Over-the-counter purchased drugs and drugs prescribed in dosages or indications not reimbursed by the NHS are not included in the analysis. Information about $\mathrm{AD}$ severity and other comorbidities, education, and social status are not available in regional drug reimbursement and prescription database. In particular, available information for each patient include age, date of birth, sex, province and prescribing district, date and number of prescriptions for Anatomical Therapeutic Chemical (ATC) code, dispensation, number of boxes, active principles, and medical specialty. The health district includes a population of 298,000 inhabitants, of whom 84,235 people older than 60 years represent those most affected by dementia. The need for written informed consent was waived owing to the use of anonymized data only. The study was conducted in accordance with the Declaration of Helsinki, and the protocol was approved (no. 31/2017) by the Ethics Committee, Section for Northern Calabria, Calabria Region, 87100, Cosenza, Italy.

This study has examined the prescriptions of AChEI (donepezil, rivastigmine, and galantamine) and memantine (N06D, according to the ATC), provided by the Regional Health Service through territorial pharmacy and by direct distribution for the 2-year period 2017-2018. This treatment identifies unequivocally patients suffering from $\mathrm{AD}$, on the 
basis of the note 85 set by the Italian Drug Regulatory Agency (AIFA). The latter note states that prescriptions of AChEI and memantine are registered in the database for reimbursement only for patients affected by $\mathrm{AD}$; in particular, the prescriptions are limited to (1) donepezil, rivastigmine, and galantamine for mild AD with MMSE between 21 and 26; donepezil, rivastigmine, galantamine, and memantine for moderate $\mathrm{AD}$ with MMSE between 10 and 20. Switch among AChEIs and memantine was not further specified in the database. In particular, two a priori hypotheses have been formulated and tested:

Hypothesis1: we have hypothesized that the number of patients receiving prescriptions of symptomatic drugs against $\mathrm{AD}$ in this real-world setting may approximate the number of patients affected by dementia in Italy [25].

Hypothesis2: we have hypothesized that adherence to the symptomatic treatment of $\mathrm{AD}$ affects the pattern of prescription of drugs for BPSD and the previously reported $[23,24]$ limited prescription of analgesics.

To test these hypotheses, the prescriptions of antipsychotics (chlorpromazine, levomepromazine, fluphenazine, periciazine, haloperidol, pimozide, clozapine, olanzapine, quetiapine, clotiapine, amisulpride, levosulpiride, risperidone, and aripiprazole), antidepressants (clomipramine, trimipramine, amitriptyline, fluoxetine, citalopram, paroxetine, sertraline, fluvoxamine, escitalopram, trazodone, mirtazapine, venlafaxine, reboxetine, duloxetine, and vortioxetine), and analgesics have been monitored and analyzed for each individual patient receiving pharmacological treatment for AD. Moreover, MMSE of patients referred to $\mathrm{CDCD}$ of the provincial health district of Cosenza has been studied to gain insight on the occurrence of delay for referral to the CDCD of patients with suspected dementia. This subgroup of the population has been stratified for sex and age, and the percentage of treatment with psychotropic drugs has been analyzed.

\section{Data analysis}

Data have been extracted from the database and analyzed through Microsoft Office Excel 2010 (Microsoft, Milan, Italy). Statistical analyses have been performed using GraphPad Prism ${ }^{\circledR} 6.0$ (GraphPad software Incorporated, San Diego, CA, USA). The results have been evaluated statistically for difference using $\chi^{2}$ test for categorical variables considering $p<0.05$ significant.

\section{Results}

\section{Stratification of the patients}

The database searched for the study belongs to a health district including 298,000 inhabitants, of whom 84,235 over 60 years of age. Within the analyzed population of 84,235 individuals, $859(1.02 \%)$ patients older than 60 years $($ females $=513$ $[59.70 \%]$; males $=346[40.30 \%])$ receive treatment with $\mathrm{AChEI}$ and memantine.

The symptomatic dementia treatment is as follows: 408 patients $(47.50 \%)$ are treated with AChEI, 298 patients (34.70\%) with memantine, and $153(17.80 \%)$ receive both AChEI and memantine. Data on the prescriptions of AChEI and memantine in the sample studied within the 2-year period $2017-2018$ show that 420 patients $(0.49 \%$ of the total sample of 84,235 individuals and $48.89 \%$ of the whole population receiving dementia treatment) are adherent to the treatment. Among these, 190 patients (45.24\% of the adherent patients) are treated with AChEI, $112(26.66 \%)$ with memantine, and $118(28.10 \%)$ with both AChEI and memantine. The stratification of patients is reported in Table 1 .

Eight hundred fifty-nine patients $(1.02 \%$ of the over 60 population considered; 346 males and 513 females) are treated for dementia in a sample of 298,000 inhabitants $(84,235$ over $60)$. In particular, 408 patients $(47.50 \%)$ are treated with acetylcholinesterase inhibitors (AChEI), 298 patients (34.70\%) with memantine, and $153(17.80 \%)$ receive both AChEI and memantine. Of these, 420 are adherent to the treatment: 190 patients $(45.24 \%$ of the adherent patients) are treated with AChEI, 112 (26.66\%) with memantine, and 118 (28.10\%) with both AChEI and memantine.

The subgroup of this population (103 patients) referred to the CDCD of the health district of Cosenza has been studied confirming the prevalence of females among demented patients (Table 2); $68.93 \%$ of the whole sample is females. The majority of patients $(62.14 \%)$ comes to clinic observation when the Mini Mental State Examination (MMSE) score is $\leq 20$ (Table 2). In this population, $19.41 \%$ and $8.73 \%$ of patients are prescribed antipsychotics and antidepressants, respectively.

Dementia is more common in females $(68.93 \%)$. Among them, $62.14 \%$ of patients comes to clinic observation at a stage of moderate-to-severe dementia (MMSE $\leq 20$ ). $19.41 \%$ of patients receives prescriptions of antipsychotics, and $8.73 \%$ of them is prescribed antidepressants.

\section{Treatment patterns of patients who are adherent/non-adherent to the therapy with AChEI and memantine}

We compared the frequency of use of drugs for BPSD (i.e. antipsychotics and antidepressants) and for pain (i.e. non- 
Table 1 Stratification of the patients

\begin{tabular}{lllll}
\hline & Patients & AChEI & Memantine & Both AChEI and memantine \\
\hline Total sample & 298,000 & & & \\
Over 60 & 84,235 & 408 & 298 & 153 \\
Treated for dementia & $859(346$ males and 513 females) & 190 & 112 & 118 \\
Adherent to treatment & 420 & & & \\
\hline
\end{tabular}

steroidal anti-inflammatory drugs (NSAIDs), opioids, gabapentinoids, lamotrigine, amitriptyline and duloxetine) in patients who were adherent vs those non-adherent to the therapy with AChEI and memantine (Fig. 1).

The results demonstrate that the pattern of antipsychotics use is almost superimposable in the two populations, i.e. adherent $(20.71 \%)$ and non-adherent $(20.61 \%)$ patients (Fig. 1). In particular, data concerning the prescriptions of antipsychotics in the adherent cluster have been analyzed for each patient, unraveling that $16.43 \%$ of these patients are treated for longer than 6-12 weeks. Antidepressants are extensively used in nonadherent patients $(42.37 \%)$ and even more in the adherent ones $(51.43 \%)$ (Fig. 1). Among antidepressants, the prescriptions of amitriptyline and duloxetine have been considered separately, since they could be used to treat both depression and/or neuropathic pain but are more commonly prescribed for the latter condition in Italy. These two drugs are used in $6.43 \%$ of adherent and $6.75 \%$ of non-adherent patients (Fig. 1).

The treatment with NSAIDs differs more than the others between adherent and non-adherent patients, showing values of $38.57 \%$ and $62.28 \%$, respectively (Fig. 1). Opioids are prescribed in $4.76 \%$ and $12.46 \%$ of adherent and nonadherent patients, respectively. There is a small amount of patients receiving treatment for neuropathic pain: gabapentin and pregabalin are used in $4.29 \%$ and $4.07 \%$ of adherent and non-adherent patients, respectively; lamotrigine is prescribed to $0.48 \%$ of adherent and $0.7 \%$ of non-adherent patients; $6.43 \%$ of adherent and $6.75 \%$ of non-adherent patients are treated with amitriptyline and duloxetine (Fig. 1). Difference between adherent and non-adherent patients for the whole dataset does not reach statistical significance $(p=0.1204)$.

\section{Discussion}

Dementia has a remarkable social burden on the global population, and data from real-world settings of community are still very scarce. Our results highlight an under-treatment of dementia since only 859 individuals receive treatment with $\mathrm{AChEI}$ and memantine, in comparison with the number of patients affected by dementia in Italy, i.e. 900 to $<1000$ per 100,000 inhabitants [25], accounting for 2700-3000 potential cases in the population we studied. These figures, however, are in keeping with reports from other European countries [26, 27]. Indeed, dementia is often underdiagnosed by clinicians or underreported by family, determining a rate of about $50 \%$ of people with dementia really receiving a diagnosis [28]. In particular, the rate of undetected dementia reaches up to $61.7 \%$ with variability among Europe, the USA, and India [29]. The underdiagnosis of dementia is often due to the severity of cognitive impairment, advanced age, and low educational level especially in rural areas [29]. The view that the limited number of patients diagnosed with dementia is one of the reasons of under-treatment is in accordance with our data from the CDCD of the same health district, where $62.14 \%$ of patients were referred with a MMSE $\leq 20$ underscoring a clinical condition of moderate-to-severe dementia. These data may stem from the lack of a healthcare diagnostic and therapeutic strategy in Calabria, a condition that, actually, occurs in the majority of Italian Regions (i.e. 13 out of 20 [30]). A longitudinal retrospective cohort study conducted in the UK from 2005 to 2015 [31] shows an increase in diagnosis and treatment of dementia and a decrease in the prescription of antipsychotics following the introduction of the UK National Dementia Strategy [31]. A recent study analyzed the prescribing rates since the launch of the symptomatic drugs for the dementia in 1997 up until 2016, reporting the factors influencing the treatment with AChEI and memantine; the latter are considered linked to regulatory strategies but not always in a predictable way [32]. This strengthens the need for national policies to improve the care of patients suffering from dementia. Another reason for the difference between the estimated

Table 2 Clinical features and treatments of 103 patients referred to the CDCD of Cosenza

\begin{tabular}{|c|c|c|c|c|c|}
\hline & Males & Females & $\mathrm{MMSE} \leq 20$ & Receiving treatment with antipsychotics & Receiving treatment with antidepressants \\
\hline$\%$ of patients & 31.07 & 68.93 & 62.14 & 19.41 & 8.73 \\
\hline
\end{tabular}




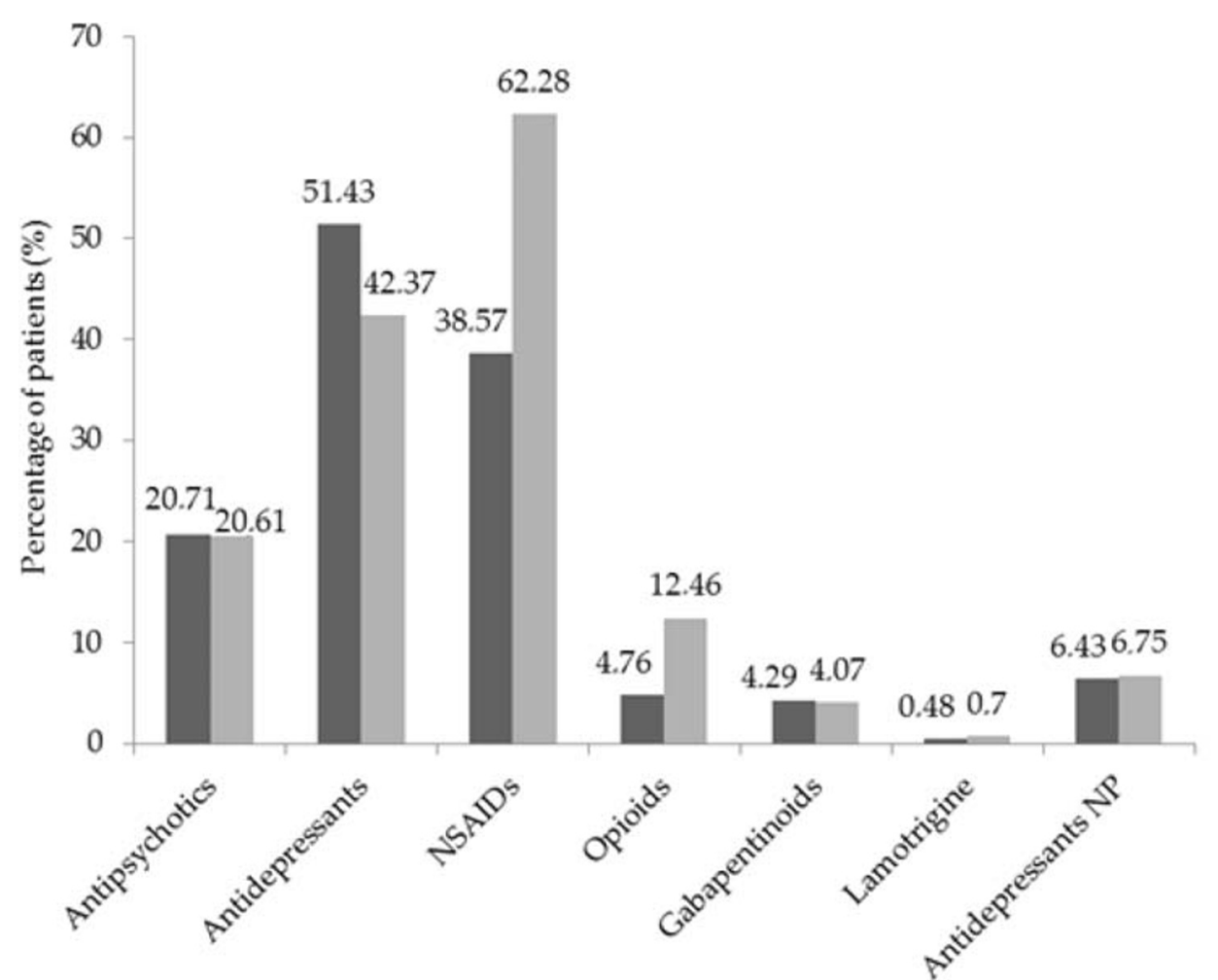

Fig. 1 Difference in treatments between patients adherent and nonadherent to the therapy with AChEI and memantine. The use of antipsychotics is almost superimposable in the adherent $(20.71 \%)$ and nonadherent $(20.61 \%)$ patients. Antidepressants are extensively used (nonadherent patients: $42.37 \%$; adherent patients: $51.43 \%$ ). The treatment with NSAIDs presents values of $38.57 \%$ for adherent and of $62.28 \%$ for non-adherent patients. Opioids are used in $4.76 \%$ and $12.46 \%$ of adherent and non-adherent patients, respectively. Gabapentinoids are used in the $4.29 \%$ and $4.07 \%$ of adherent and non-adherent patients, respectively. $0.48 \%$ of adherent and $0.7 \%$ of non-adherent patients are treated with lamotrigine. $6.43 \%$ of adherent and $6.75 \%$ of non-adherent patients receive treatment with antidepressants used for neuropathic pain (NP). Data are expressed as percentages and evaluated statistically for difference considering $p<0.05$ significant ( $\chi^{2}$ test: $p=0.1204$ ) number of demented people and those prescribed with $\mathrm{AChEI}$ and memantine is that these drugs are reimbursed by the NHS only for patients with MMSE $>10$.

An important issue is the non-adherence to the therapy with AChEI and memantine, a serious problem since it is responsible for inadequate treatment of cognitive decline and exacerbation of BPSD [13]. According to WHO, the definition of adherence is the extent to which a person's behaviour, taking medication, corresponds with agreed recommendations from a health care provider [33]. Adherence to treatment is defined as percentage of prescribed medication taken, and according to the most frequently used cutoff of $80 \%$, the degree of a medication use corresponding or aligning with the recommendations of the prescriber and missing $20 \%$ or more of the medication defines nonadherence [34-38]. Conceivably, adherent patients are subjected to more frequent physical examination which can include pain assessment. Indeed, a link between accurate medical care and medication adherence has been found [39]. Our data demonstrate the lack of accurate adherence to dementia treatment, in that only 420 patients out of 859 patients receiving anti-dementia treatment $(48.89 \%)$ have been found adherent. Non-adherence and discontinuation of the medication in dementia increases the risk of hospitalization and death [40]. In line with a previous European study reporting disease progression on cognitive or functional scales to be among the factors reducing adherence to anti-dementia drugs [41], we may speculate that nonadherence might be related to delayed dementia diagnosis in our sample. However, AChEI and memantine are often prescribed, sometimes inappropriately, in patients with vascular dementia, synucleinopathies, frontotemporal dementia, and other conditions, this point representing a potential bias. Prescription of antipsychotics in our patients, either adherent or non-adherent, is in the lower part of the range (i.e. 20-30\%) reported in previous studies [8], likely because we recruited patients in the community rather than in long-term care settings [8]. However, the rate of use of antidepressants is noteworthy ( $42.37 \%$ of non-adherent patients and $51.43 \%$ of adherent patients). Difference between adherent and non-adherent patients in this context does not reach statistical significance, suggesting that adherence to symptomatic anti-dementia drugs does not impact the prescriptions of the latter drugs. Memantine is associated to some efficacy in agitation, which however is controversial [42]; in particular, there is an effect on the development of 
new agitation, but no evidence on already existing agitation [43]. Indeed, the use of anti-dementia drugs, in particular memantine, has been associated with fewer BPSD [44, 45] and a reduced rate of slope for monthly use of antipsychotics $[46,47]$. The latter evidence is in line with clinical trials [48, 49] and Cochrane meta-analysis [43] showing the effect of this drug on the development of agitation. However, the stronger effect of memantine as compared with AChEI is seen in an advanced stage of dementia where BPSD are often more severe [46]. At variance with the latter, evidence from clinical trials does not support the efficacy of AChEI and memantine in the treatment of depressive symptoms associated to dementia [50]. Unfortunately, antipsychotics have been often used for more than 6-12 weeks in our sample, increasing their potential for toxicity [13]. A percentage of antidepressants in this population might have been prescribed for neuropathic pain. A high rate of use of antidepressants has been described also in other European countries [51-55]. This aspect has a fundamental importance because, despite the potential of antidepressants for neurogenesis [56, 57], the use of drugs endowed with anticholinergic burden can worsen cognitive decline, increase the risk of falls, institutionalization, and mortality [58-65]. Therefore, antidepressants in demented patients should be prescribed only after appropriate diagnosis and with regular follow-up, since the efficacy and safety of these drugs still awaits support from large, rigorous clinical trials [66, 67]. Psychotropic polypharmacy has been described also in Denmark. Indeed, an overlapping treatment with at least 2 psychotropic drugs has been reported in $25.3 \%$ of demented patients in a Danish populationbased study [68]. Interestingly, our data demonstrate that patients who are referred to CDCD receive fewer prescriptions; indeed, only $19.41 \%$ and $8.73 \%$ of patients are prescribed antipsychotics and antidepressants, respectively, and this may stem from a better control of dementia and regular follow-up. Pain could not be recorded in our samples because of the retrospective design of the study and the difficulty of measuring pain in demented patient. However, comparison of our data with previous reports from the UK, where strong opioids are used in $83.9 \%$ of noncancer patients (mean age $67.1 \pm 17.0$ years) [69], suggests chronic pain to be under-treated in both adherent and nonadherent patients, despite a larger percentage of non-adherent patients being prescribed NSAIDS. Also, the percentage of patients receiving treatment for neuropathic pain is low and, to the best of our knowledge, this is the first study performed on a very large sample including community patients that has highlighted the prescribing attitude towards drugs for neuropathic pain treatment in patients suffering from dementia. This is in line with international epidemiological research showing that demented patients are prescribed fewer pain medications than cognitively intact aged patients [17]. Some patients were under antiepileptic drugs, and epilepsy may occur in demented patients. However, gabapentin and pregabalin are rarely used to treat epilepsy very seldom because of their poor efficacy, while lamotrigine is slow to titrate and not practical in a demented patient.

The above described issues in the management of pain in patients affected by severe dementia are likely due to the lack of an accurate diagnosis because of their reduced communication skills. Moreover, the paucity of studies investigating pharmacodynamics, efficacy, and safety of drugs in demented patients results in poor pain treatment [17]. Therefore, clinical trials evaluating the various treatments used in patients suffering from dementia are needed. Moreover, the adoption of national policies to handle dementia and pain in cognitively impaired patients are mandatory to improve pain assessment and the treatment of BPSD, reducing the off label use of unnecessary psychotropic drugs. Non-pharmacological treatments for the management of BPSD have proven efficacy devoid of the toxicity of atypical antipsychotics [13]. Among others, aromatherapy with Melissa has provided evidence for reduction of agitation [70]. Interestingly, the essential oil of bergamot is endowed with powerful analgesic (see $[12,71,72]$ ) and anxiolytic, nonbenzodiazepine-like properties $[73,74]$ forming the rational basis for a starting clinical trial (NCT04321889) exploring whether it may represent a safe and effective treatment of BPSD.

Limitations of the present study include the retrospective design and the inclusion of a single health district that may not be representative of the whole Italian population though it might form the rational basis for regional regulatory intervention. Moreover, the regional drug reimbursement and prescription database does not include over-the-counter purchased drugs and drugs prescribed in dosages not reimbursed by the NHS. Future multicenter studies will overcome these limitations.

Authors' contributions MTC, LAM, GS, ST, PT, and GB conceived the study and supervised the manuscript. DS participated in the design of the study, analyzed the data, searched the literature, and wrote the manuscript. MV, BP, and RBB collected the data. All authors read and approved the final manuscript.

Funding Open access funding provided by Università della Calabria within the CRUI-CARE Agreement. D.S. is a post-doc recipient of a research grant salary in the frame of a research project (Tutor: Giacinto Bagetta) on "Pharmacoepidemiology of drugs used in the treatment of neuropsychiatric symptoms and pain in aged (over 65) people with dementia" funded by Calabria Region (POR Calabria FESR-FSE 2014/2020-Linea B) Azione 10.5.12.

Data availability All the dataset created are reported in this manuscript.

\section{Compliance with ethical standards}

Conflicts of interest The authors declare that they have no conflict of interest.

Ethics approval The study was conducted in accordance with the Declaration of Helsinki, and the protocol was approved (no. 31/2017) by the Ethics Committee, Section for Northern Calabria, Calabria Region, 87100, Cosenza, Italy, registered on October 31, 2017. 
Consent to participate The study was carried out using retrospectively collected and anonymized data. The need for written informed consent was waived owing to the retrospective nature of the study.

Consent for publication The study was carried out using retrospectively collected and anonymized data; therefore, the consent for publication was not needed.

Open Access This article is licensed under a Creative Commons Attribution 4.0 International License, which permits use, sharing, adaptation, distribution and reproduction in any medium or format, as long as you give appropriate credit to the original author(s) and the source, provide a link to the Creative Commons licence, and indicate if changes were made. The images or other third party material in this article are included in the article's Creative Commons licence, unless indicated otherwise in a credit line to the material. If material is not included in the article's Creative Commons licence and your intended use is not permitted by statutory regulation or exceeds the permitted use, you will need to obtain permission directly from the copyright holder. To view a copy of this licence, visit http://creativecommons.org/licenses/by/4.0/.

\section{References}

1. Patterson C (2018) World Alzheimer Report 2018. The state of the art of dementia research: new frontiers. Alzheimer's Disease International (ADI), London

2. Scuteri D, Morrone LA, Rombola L, Avato PR, Bilia AR, Corasaniti MT, Sakurada S, Sakurada T, Bagetta G (2017) Aromatherapy and aromatic plants for the treatment of behavioural and psychological symptoms of dementia in patients with Alzheimer's disease: clinical evidence and possible mechanisms. Evidence-Based Complement Altern Med eCAM 2017:94163059416308. https://doi.org/10.1155/2017/9416305

3. Scuteri D, Rombola L, Tridico L, Mizoguchi H, Watanabe C, Sakurada T, Sakurada S, Corasaniti MT, Bagetta G, Morrone LA (2019) Neuropharmacological properties of the essential oil of bergamot for the clinical management of pain-related BPSDs. Curr Med Chem 26(20):3764-3774. https://doi.org/10.2174/ 0929867325666180307115546

4. Vernooij-Dassen MJ, Moniz-Cook ED, Woods RT, De Lepeleire J, Leuschner A, Zanetti O, de Rotrou J, Kenny G, Franco M, Peters V, Iliffe $\mathrm{S}$ (2005) Factors affecting timely recognition and diagnosis of dementia across Europe: from awareness to stigma. Int J Geriatric Psych 20(4):377-386. https://doi.org/10.1002/gps.1302

5. Gove D, Downs M, Vernooij-Dassen M, Small N (2016) Stigma and GPs' perceptions of dementia. Aging Ment Health 20(4):391400. https://doi.org/10.1080/13607863.2015.1015962

6. Parmar J, Dobbs B, McKay R, Kirwan C, Cooper T, Marin A, Gupta N (2014) Diagnosis and management of dementia in primary care: exploratory study. Canadian family physician Medecin de famille canadien 60(5):457-465

7. Valcour VG, Masaki KH, Curb JD, Blanchette PL (2000) The detection of dementia in the primary care setting. Arch Intern Med 160(19):2964-2968. https://doi.org/10.1001/archinte.160.19. 2964

8. Kirkham J, Sherman C, Velkers C, Maxwell C, Gill S, Rochon P, Seitz D (2017) Antipsychotic use in dementia. Can J Psychiatr 62(3):170-181. https://doi.org/10.1177/0706743716673321

9. Steinberg M, Shao H, Zandi P, Lyketsos CG, Welsh-Bohmer KA, Norton MC, Breitner JC, Steffens DC, Tschanz JT, Cache County I (2008) Point and 5-year period prevalence of neuropsychiatric symptoms in dementia: the Cache County Study. Int J Geriatric Psych 23(2):170-177. https://doi.org/10.1002/gps.1858

10. Wise EA, Rosenberg PB, Lyketsos CG, Leoutsakos JM (2019) Time course of neuropsychiatric symptoms and cognitive diagnosis in National Alzheimer's Coordinating Centers volunteers. Alzheimers Dement (Amst) 11:333-339. https://doi.org/10.1016/j. dadm.2019.02.006

11. Vik-Mo AO, Giil LM, Ballard C, Aarsland D (2018) Course of neuropsychiatric symptoms in dementia: 5-year longitudinal study. Int J Geriatric Psych 33(10):1361-1369. https://doi.org/10.1002/ gps.4933

12. Scuteri D, Rombola L, Morrone LA, Bagetta G, Sakurada S, Sakurada T, Tonin P, Corasaniti MT (2019) Neuropharmacology of the neuropsychiatric symptoms of dementia and role of pain: essential oil of bergamot as a novel therapeutic approach. Int $\mathbf{J}$ Mol Sci 20(13). https://doi.org/10.3390/ijms20133327

13. Ballard CG, Gauthier S, Cummings JL, Brodaty H, Grossberg GT, Robert P, Lyketsos CG (2009) Management of agitation and aggression associated with Alzheimer disease. Nat Rev Neurol 5(5): 245-255. https://doi.org/10.1038/nrneurol.2009.39

14. Schneider LS, Dagerman KS, Insel P (2005) Risk of death with atypical antipsychotic drug treatment for dementia: meta-analysis of randomized placebo-controlled trials. Jama 294(15):1934-1943. https://doi.org/10.1001/jama.294.15.1934

15. Duncan R, Francis RM, Collerton J, Davies K, Jagger C, Kingston A, Kirkwood T, Robinson L, Birrell F (2011) Prevalence of arthritis and joint pain in the oldest old: findings from the Newcastle $85+$ study. Age Ageing 40(6):752-755. https://doi.org/10.1093/ageing/ afr 105

16. Achterberg WP (2019) How can the quality of life of older patients living with chronic pain be improved? Pain Manag 9(5):431-433. https://doi.org/10.2217/pmt-2019-0023

17. Achterberg WP, Pieper MJ, van Dalen-Kok AH, de Waal MW, Husebo BS, Lautenbacher S, Kunz M, Scherder EJ, Corbett A (2013) Pain management in patients with dementia. Clin Interv Aging 8:1471-1482. https://doi.org/10.2147/CIA.S36739

18. Sampson EL, White N, Lord K, Leurent B, Vickerstaff V, Scott S, Jones L (2015) Pain, agitation, and behavioural problems in people with dementia admitted to general hospital wards: a longitudinal cohort study. Pain 156(4):675-683. https://doi.org/10.1097/j.pain. 0000000000000095

19. Husebo BS, Ballard C, Sandvik R, Nilsen OB, Aarsland D (2011) Efficacy of treating pain to reduce behavioural disturbances in residents of nursing homes with dementia: cluster randomised clinical trial. Bmj 343:d4065. https://doi.org/10.1136/bmj.d4065

20. Doan L, Manders T, Wang J (2015) Neuroplasticity underlying the comorbidity of pain and depression. Neural Plastic 2015:504691504616. https://doi.org/10.1155/2015/504691

21. Whitlock EL, Diaz-Ramirez LG, Glymour MM, Boscardin WJ, Covinsky KE, Smith AK (2017) Association between persistent pain and memory decline and dementia in a longitudinal cohort of elders. JAMA Intern Med 177(8):1146-1153. https://doi.org/10. 1001/jamainternmed.2017.1622

22. Ezzati A, Wang C, Katz MJ, Derby CA, Zammit AR, Zimmerman ME, Pavlovic JM, Sliwinski MJ, Lipton RB (2019) The temporal relationship between pain intensity and pain interference and incident dementia. Curr Alzheimer Res 16(2):109-115. https://doi.org/ $10.2174 / 1567205016666181212162424$

23. Scuteri D, Piro B, Morrone LA, Corasaniti MT, Vulnera M, Bagetta $\mathrm{G}$ (2017) The need for better access to pain treatment: learning from drug consumption trends in the USA. Funct Neurol 22(4):229-230. https://doi.org/10.11138/fneur/2017.32.4.229

24. Scuteri D, Garreffa MR, Esposito S, Bagetta G, Naturale MD, Corasaniti MT (2018) Evidence for accuracy of pain assessment and painkillers utilization in neuropsychiatric symptoms of 
dementia in Calabria region, Italy. Neural Regen Res 13(9):16191621. https://doi.org/10.4103/1673-5374.237125

25. Collaborators GBDD (2019) Global, regional, and national burden of Alzheimer's disease and other dementias, 1990-2016: a systematic analysis for the Global Burden of Disease Study 2016. Lancet Neurol 18(1):88-106. https://doi.org/10.1016/S1474-4422(18) 30403-4

26. Zakarias JK, Jensen-Dahm C, Norgaard A, Roos P, Gasse C, Phung TKT, Waldemar G (2019) Geographical variation in the diagnostic rate and quality of dementia diagnoses. J Alzheimer's Dis JAD 69(2):513-520. https://doi.org/10.3233/JAD-190030

27. https://assets.publishing.service.gov.uk/government/uploads/ system/uploads/attachment_data/file/262139/Dementia.pdf DoHU (.).

28. Amjad H, Roth DL, Sheehan OC, Lyketsos CG, Wolff JL, Samus QM (2018) Underdiagnosis of dementia: an observational study of patterns in diagnosis and awareness in US older adults. J Gen Intern Med 33(7):1131-1138. https://doi.org/10.1007/s11606-018-4377$\mathrm{y}$

29. Lang L, Clifford A, Wei L, Zhang D, Leung D, Augustine G, Danat IM, Zhou W, Copeland JR, Anstey KJ, Chen R (2017) Prevalence and determinants of undetected dementia in the community: a systematic literature review and a meta-analysis. BMJ Open 7(2): e011146. https://doi.org/10.1136/bmjopen-2016-011146

30. https://www.epicentro.iss.it/alzheimer/world-alzheimer-day-2019. NIoHI (.).

31. Donegan K, Fox N, Black N, Livingston G, Banerjee S, Burns A (2017) Trends in diagnosis and treatment for people with dementia in the UK from 2005 to 2015: a longitudinal retrospective cohort study. Lancet Public Health 2(3):e149-e156. https://doi.org/10. 1016/S2468-2667(17)30031-2

32. Walker VM, Davies NM, Kehoe PG, Martin RM (2018) What is the impact of regulatory guidance and expiry of drug patents on dementia drug prescriptions in England? A trend analysis in the Clinical Practice Research Datalink. Alzheimers Res Ther 10(1): 51. https://doi.org/10.1186/s13195-018-0379-6

33. Sabate E (2001) WHO Adherence Meeting Report. World Health Organization, Geneva

34. Phan SV (2016) Medication adherence in patients with schizophrenia. Int J Psychiatry Med 51(2):211-219. https://doi.org/10.1177/ 0091217416636601

35. Engelkes M, Janssens HM, de Jongste JC, Sturkenboom MC, Verhamme KM (2015) Medication adherence and the risk of severe asthma exacerbations: a systematic review. Eur Respir J 45(2):396407. https://doi.org/10.1183/09031936.00075614

36. Souverein PC, Koster ES, Colice G, van Ganse E, Chisholm A, Price D, Dima AL, Respiratory Effectiveness Group's Adherence Working G (2017) Inhaled corticosteroid adherence patterns in a longitudinal asthma cohort. J Allergy Clin Immunol Pract 5(2): 448-456 e442. https://doi.org/10.1016/j.jaip.2016.09.022

37. Papi A, Ryan D, Soriano JB, Chrystyn H, Bjermer L, RodriguezRoisin R, Dolovich MB, Harris M, Wood L, Batsiou M, Thornhill SI, Price DB (2018) Relationship of inhaled corticosteroid adherence to asthma exacerbations in patients with moderate-to-severe asthma. J Allergy Clin Immunol Pract 6(6):1989-1998 e1983. https://doi.org/10.1016/j.jaip.2018.03.008

38. Vahatalo I, Ilmarinen P, Tuomisto LE, Tommola M, Niemela O, Lehtimaki L, Nieminen P, Kankaanranta H (2020) 12-year adherence to inhaled corticosteroids in adult-onset asthma. ERJ Open Res 6(1):00324-02019. https://doi.org/10.1183/23120541.003242019

39. Algameel M (2020) Patterns of medication use and adherence to medications among residents in the elderly homes. Pakistan $\mathrm{J}$ Medic Sci 36(4):729-734. https://doi.org/10.12669/pjms.36.4. 1923
40. El-Saifi N, Moyle W, Jones C, Tuffaha H (2018) Medication adherence in older patients with dementia: a systematic literature review. J Pharm Pract 31(3):322-334. https://doi.org/10.1177/ 0897190017710524

41. Gardette V, Lapeyre-Mestre M, Piau A, Gallini A, Cantet C, Montastruc JL, Vellas B, Andrieu S, Group I (2014) A 2-year prospective cohort study of antidementia drug non-persistency in mild-to-moderate Alzheimer's disease in Europe : predictors of discontinuation and switch in the ICTUS study. CNS Drugs 28(2):157-170. https://doi.org/10.1007/s40263-013-0133-3

42. McShane R, Westby MJ, Roberts E, Minakaran N, Schneider L, Farrimond LE, Maayan N, Ware J, Debarros J (2019) Memantine for dementia. Cochrane Database Syst Rev 3:CD003154. https:// doi.org/10.1002/14651858.CD003154.pub6

43. McShane R, Areosa Sastre A, Minakaran N (2006) Memantine for dementia. Cochrane Database Syst Rev 2:CD003154. https://doi. org/10.1002/14651858.CD003154.pub5

44. de Oliveira FF, Bertolucci PH, Chen ES, Smith Mde A (2014) Pharmacological modulation of cognitive and behavioral symptoms in patients with dementia due to Alzheimer's disease. J Neurol Sci 336(1-2):103-108. https://doi.org/10.1016/j.jns.2013. 10.015

45. Scharre DW, Vekeman F, Lefebvre P, Mody-Patel N, Kahler KH, Duh MS (2010) Use of antipsychotic drugs in patients with Alzheimer's disease treated with rivastigmine versus donepezil: a retrospective, parallel-cohort, hypothesis-generating study. Drugs Aging 27(11):903-913. https://doi.org/10.2165/11584290000000000-00000

46. Martinez C, Jones RW, Rietbrock S (2013) Trends in the prevalence of antipsychotic drug use among patients with Alzheimer's disease and other dementias including those treated with antidementia drugs in the community in the UK: a cohort study. BMJ Open 3(1):e002080. https://doi.org/10.1136/bmjopen-2012002080

47. Lachaine J, Beauchemin C, Crochard A, Bineau S (2013) The impact of memantine and cholinesterase inhibitor initiation for Alzheimer disease on the use of antipsychotic agents: analysis using the Regie de l'Assurance Maladie du Quebec database. Can J Psychiatr 58(4):195-200. https://doi.org/10.1177/ 070674371305800404

48. Wilcock GK, Ballard CG, Cooper JA, Loft H (2008) Memantine for agitation/aggression and psychosis in moderately severe to severe Alzheimer's disease: a pooled analysis of 3 studies. J Clin Psychol 69(3):341-348. https://doi.org/10.4088/jcp.v69n0302

49. Gauthier S, Loft H, Cummings J (2008) Improvement in behavioural symptoms in patients with moderate to severe Alzheimer's disease by memantine: a pooled data analysis. Int J Geriatric Psych 23(5):537-545. https://doi.org/10.1002/gps. 1949

50. Ford AH, Almeida OP (2017) Management of depression in patients with dementia: is pharmacological treatment justified? Drugs Aging 34(2):89-95. https://doi.org/10.1007/s40266-016-0434-6

51. Majic T, Pluta JP, Mell T, Aichberger MC, Treusch Y, Gutzmann H, Heinz A, Rapp MA (2010) The pharmacotherapy of neuropsychiatric symptoms of dementia: a cross-sectional study in 18 homes for the elderly in Berlin. Deutsches Arzteblatt Int 107(18):320-327. https://doi.org/10.3238/arzteb1.2010.0320

52. Giebel CM, Sutcliffe C, Renom-Guiteras A, Arve S, Hallberg IR, Soto M, Zabalegui A, Hamers J, Saks K, Challis D (2015) Depressive symptomatology in severe dementia in a European sample: prevalence, associated factors and prescription rate of antidepressants. Int Psychogeriatr 27(4):657-667. https://doi.org/10. 1017/S1041610214002610

53. Laitinen ML, Lonnroos E, Bell JS, Lavikainen P, Sulkava R, Hartikainen S (2015) Use of antidepressants among communitydwelling persons with Alzheimer's disease: a nationwide register- 
based study. Int Psychogeriatr 27(4):669-672. https://doi.org/10. 1017/S1041610214002427

54. Breining A, Bonnet-Zamponi D, Zerah L, Micheneau C, RiolacciDhoyen N, Chan-Chee C, Deligne J, Harlin JM, Boddaert J, Verny M, Leperre-Desplanques A (2017) Exposure to psychotropics in the French older population living with dementia: a nationwide population-based study. Int J Geriatric Psych 32(7):750-760. https://doi.org/10.1002/gps.4517

55. Hessmann P, Zeidler J, Stahmeyer J, Eberhard S, Vogelgsang J, Abdel-Hamid M, Wolff-Menzler C, Wiltfang J, Kis B (2019) Claims data analysis on the dispensing of tricyclic antidepressants among patients with dementia in Germany. Front Pharmacol 10: 841. https://doi.org/10.3389/fphar.2019.00841

56. Malberg JE, Eisch AJ, Nestler EJ, Duman RS (2000) Chronic antidepressant treatment increases neurogenesis in adult rat hippocampus. J Neurosci 20(24):9104-9110

57. Kim HJ, Kim W, Kong SY (2013) Antidepressants for neuro-regeneration: from depression to Alzheimer's disease. Arch Pharm Res 36(11):1279-1290. https://doi.org/10.1007/s12272-013-02388

58. Landi F, Russo A, Liperoti R, Cesari M, Barillaro C, Pahor M, Bernabei R, Onder G (2007) Anticholinergic drugs and physical function among frail elderly population. Clin Pharmacol Ther 81(2):235-241. https://doi.org/10.1038/sj.clpt.6100035

59. Pasina L, Djade CD, Lucca U, Nobili A, Tettamanti M, Franchi C, Salerno F, Corrao S, Marengoni A, Iorio A, Marcucci M, Violi F, Mannucci PM (2013) Association of anticholinergic burden with cognitive and functional status in a cohort of hospitalized elderly: comparison of the anticholinergic cognitive burden scale and anticholinergic risk scale: results from the REPOSI study. Drugs Aging 30(2):103-112. https://doi.org/10.1007/s40266-012-0044-x

60. Landi F, Dell'Aquila G, Collamati A, Martone AM, Zuliani G, Gasperini B, Eusebi P, Lattanzio F, Cherubini A (2014) Anticholinergic drug use and negative outcomes among the frail elderly population living in a nursing home. J Am Med Dir Assoc 15(11):825-829. https://doi.org/10.1016/j.jamda.2014.08.002

61. Boccardi V, Baroni M, Paolacci L, Ercolani S, Longo A, Giordano M, Ruggiero C, Mecocci P (2017) Anticholinergic burden and functional status in older people with cognitive impairment: results from the regal project. J Nutr Health Aging 21(4):389-396. https:// doi.org/10.1007/s12603-016-0787-x

62. Ruxton K, Woodman RJ, Mangoni AA (2015) Drugs with anticholinergic effects and cognitive impairment, falls and all-cause mortality in older adults: a systematic review and meta-analysis. Br J Clin Pharmacol 80(2):209-220. https://doi.org/10.1111/bcp.12617

63. Egberts A, van der Craats ST, van Wijk MD, Alkilabe S, van den Bemt P, Mattace-Raso FUS (2017) Anticholinergic drug exposure is associated with delirium and postdischarge institutionalization in acutely ill hospitalized older patients. Pharmacol Res Perspect 5(3): e00310. https://doi.org/10.1002/prp2.310

64. Collamati A, Martone AM, Poscia A, Brandi V, Celi M, Marzetti E, Cherubini A, Landi F (2016) Anticholinergic drugs and negative outcomes in the older population: from biological plausibility to clinical evidence. Aging Clin Exp Res 28(1):25-35. https://doi. org/10.1007/s40520-015-0359-7

65. De Vreese LP, Mantesso U, De Bastiani E, Marangoni A, Weger E, Gomiero T (2018) Anticholinergic burden in adult and elderly people with intellectual disabilities: results from an Italian multicenter cross-sectional study. PLoS ONE 13(10):e0205897. https://doi.org/ 10.1371/journal.pone.0205897

66. Choe YM, Kim KW, Jhoo JH, Ryu SH, Seo EH, Sohn BK, Byun MS, Bak JH, Lee JM, Yun HJ, Han MI, Woo JI, Lee DY (2016) Multicenter, randomized, placebo-controlled, double-blind clinical trial of escitalopram on the progression-delaying effects in Alzheimer's disease. Int J Geriatric Psych 31(7):731-739. https:// doi.org/10.1002/gps.4384

67. An H, Choi B, Park KW, Kim DH, Yang DW, Hong CH, Kim SY, Han SH (2017) The effect of escitalopram on mood and cognition in depressive Alzheimer's disease subjects. J Alzheimer's Dis JAD 55(2):727-735. https://doi.org/10.3233/JAD-160225

68. Norgaard A, Jensen-Dahm C, Gasse C, Hansen ES, Waldemar G (2017) Psychotropic polypharmacy in patients with dementia: prevalence and predictors. J Alzheimer's Dis JAD 56(2):707-716. https://doi.org/10.3233/JAD-160828

69. Zin CS, Chen LC, Knaggs RD (2014) Changes in trends and pattern of strong opioid prescribing in primary care. Eur J Pain 18(9):13431351. https://doi.org/10.1002/j.1532-2149.2014.496.x

70. Ballard CG, O'Brien JT, Reichelt K, Perry EK (2002) Aromatherapy as a safe and effective treatment for the management of agitation in severe dementia: the results of a double-blind, placebo-controlled trial with Melissa. J Clin Psychol 63(7):553558

71. Scuteri D, Crudo M, Rombola L, Watanabe C, Mizoguchi H, Sakurada S, Sakurada T, Greco R, Corasaniti MT, Morrone LA, Bagetta G (2018) Antinociceptive effect of inhalation of the essential oil of bergamot in mice. Fitoterapia 129:20-24. https://doi.org/ 10.1016/j.fitote.2018.06.007

72. Bagetta G, Morrone LA, Rombola L, Amantea D, Russo R, Berliocchi L, Sakurada S, Sakurada T, Rotiroti D, Corasaniti MT (2010) Neuropharmacology of the essential oil of bergamot. Fitoterapia 81(6):453-461. https://doi.org/10.1016/j.fitote.2010. 01.013

73. Rombolà L, Scuteri D, Adornetto A, Straface A, Sakurada T, Sakurada S, Mizoguchi H, Corasaniti MT, Bagetta G, Tonin P, Morrone LA (2019) Anxiolytic-like effects of bergamot essential oil are insensitive to flumazenil in rat. Evid Based Complement Alternat Med 2019:2156873-2156876. https://doi.org/10.1155/ 2019/2156873

74. Rombola L, Tridico L, Scuteri D, Sakurada T, Sakurada S, Mizoguchi H, Avato P, Corasaniti MT, Bagetta G, Morrone LA (2017) Bergamot essential oil attenuates anxiety-like behaviour in rats. Molecules 22(4). https://doi.org/10.3390/molecules22040614

Publisher's note Springer Nature remains neutral with regard to jurisdictional claims in published maps and institutional affiliations. 